\title{
EDITORIAL
}

\section{The Late Emeritus Professor Lester A Mitscher, a great scientist and teacher}

The Journal of Antibiotics (2016) 69, 579; doi:10.1038/ja.2016.84

$\mathrm{T}^{\mathrm{h}}$ his issue of the Journal is devoted to the memory of Lester Mitscher with contributions substantially from his colleagues and friends. (There is a degree of redundancy in that phrase, in that it was virtually impossible to be a colleague of Les without being his friend.) Les had a great love of natural products and antibiotics in particular following his graduate work on diterpenes from Coffea arabica, and his first employment at Lederle Laboratories where he headed up the tetracycline research project and became an expert in antibiotics. After he moved to academia he was in demand as a consultant to several pharmaceutical, and later biotechnology, companies. In his 37 years in this capacity at Abbott Laboratories he was always meeting with both microbiologists and chemists in the antibiotic discovery projects. After he assumed the chairmanship of the Department of Medicinal Chemistry at the University of Kansas he determined to maintain the reputation of that department, which had been built by the late Edward Smissman; and he did! In addition to being a great research scientist, he was a superb teacher. The lecture course he gave at Abbott on 'Practical Medicinal Chemistry' was one of the best attended in Abbott's Pharmaceutical Research Division. His work on antiinfectives at Kansas encompassed synthesis, semi-synthesis, mode-ofaction and biosynthetic studies, many in collaboration with colleagues working in industry.

Despite Les's training of more than 70 doctoral and postdoctoral scientists and his love of natural products and antibiotics in particular, relatively few of his trainees are currently working in this field, and hence many of the articles in this issue come from colleagues in the
American Society of Pharmacognosy, of which he was a pastpresident, or from fellow JA Editorial Board members. Les was a member of the Board from 1974 until his passing, last year. Dr. Morimasa Yagisawa, a long-time Managing Editor of the Journal had done his post-doctoral training with Les at Kansas.

The broad scope of the articles in this issue reflects Les's panoramic interest and expertise in the science of drug discovery. He would have been particularly interested in the two articles on tetracyclines, one on mode of action and the other on Eravacycline, a new fluorocycline with impressive gram negative activity. $\mathrm{He}$ also had a great interest in the discovery process and there are new microbial metabolites described here, which have been discovered by classical bioactivity screening using very novel screens, by genomic analysis of well plowed organisms, and an approach of broad data analysis. I believe this is a fitting tribute to a great man and it was my pleasure to coordinate the solicitation and review of articles as guest editor of this issue.

\section{CONFLICT OF INTEREST}

The author declares no conflict of interest.

James McAlpine

Department of Medicinal Chemistry and Pharmacognosy, College of Pharmacy, University of Illinois at Chicago,

Chicago, IL, USA

E-mail: mcalpine@uic.edu 